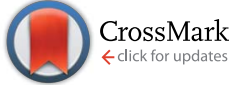

Cite this: RSC Adv., 2015, 5, 43620
Received 31st March 2015

Accepted 29th April 2015

DOI: $10.1039 / \mathrm{c} 5 \mathrm{ra0} 5702 \mathrm{~g}$

www.rsc.org/advances

\section{Synthesis of 5-aryl-3-C-glycosyl- and unsymmetrical 3,5-diaryl-1,2,4-triazoles from alkylidene-amidrazones $\dagger$}

\author{
Béla Szőcs, Éva Bokor, Katalin E. Szabó, Attila Kiss-Szikszai, Marietta Tóth* \\ and László Somsák*
}

Among 1,2,4-triazole derivatives with versatile biological activities 3-C-glucopyranosyl-5-substituted1,2,4-triazoles belong to the most efficient inhibitors of glycogen phosphorylase, and are thus potential antidiabetic agents. In seeking new synthetic methods for this class of compounds oxidative ring closures of $N^{1}$-alkylidene carboxamidrazones were studied. O-Peracylated $N^{1}-(\beta$-Dglycopyranosylmethylidene)-arenecarboxamidrazones were prepared from the corresponding glycosyl cyanides and amidrazones by Raney- $\mathrm{Ni}{ }^{\circledR}$ reduction in the presence of $\mathrm{NaH}_{2} \mathrm{PO}_{2}$. Bromination of the so obtained compounds by NBS gave hydrazonoyl bromide type derivatives which were ring closed to 3-Cglycosyl-5-substituted-1,2,4-triazoles in pyridine or by $\mathrm{NH}_{4} \mathrm{OAc}$ in $\mathrm{AcOH}$. Under the same conditions $\mathrm{O}$ perbenzoylated $N^{1}$-arylidene-C-( $\beta$-D-glucopyranosyl)-formamidrazones gave the expected 1,2,4triazoles as minor products only. $N^{1}$-Arylidene-arenecarboxamidrazones were also transformed into 3,5diaryl-1,2,4-triazoles with $\mathrm{NBS} / \mathrm{NH}_{4} \mathrm{OAc}$ in $\mathrm{AcOH}$ indicating high functional group tolerance and general applicability of the method.

\section{Introduction}

In the past few decades 1,2,4-triazole derivatives received great attention due to their broad applicability as medicinal agents. Among others, 1,2,4-triazoles have shown enormous potential as antifungal, anticancer, antibacterial, antitubercular, antiviral, anti-inflammatory, analgesic, anticonvulsant, antiparasitic, antidiabetic, antiobesitic, antihistaminic, antineuropathic, and antihypertensive medications in clinical use. $^{\mathbf{1 - 3}}$ Notably, topiroxostat, a drug approved in 2013 for the treatment of hyperuricemia and gout, has an unsymmetrical 3,5-dipyridyl-1,2,4-triazole scaffold. ${ }^{4}$

The importance of this heterocyclic moiety resulted in the development of many practical synthetic routes to 1,2,4-triazole derivatives. The majority of the methods relies on the intramolecular cyclization of acylamidrazone intermediates obtained from the reaction of amides, thioamides, imidates, nitriles, and acid chlorides with acylhydrazines or amidrazones.,5,6 Another versatile method for the syntheses of 1,2,4-triazoles is the 1,3-dipolar cycloaddition of nitriles with nitrilimines generated in situ from hydrazonoyl chlorides or substituted tetrazoles.,

Department of Organic Chemistry, University of Debrecen, POB 20, H-4010 Debrecen, Hungary. E-mail: toth.marietta@science.unideb.hu; somsak.laszlo@science.unideb.hu; Fax: +36 52512744; Tel: +36 52512900 ext. 22474; +36 52512900 ext. 22348

$\uparrow$ Electronic supplementary information (ESI) available: See DOI: 10.1039/c5ra05702g
We have recently shown that $C$-glucopyranosyl 1,2,4-triazoles represent one of the most efficient type of glucose analogue inhibitors of glycogen phosphorylase (e.g. compound $\mathbf{J}$ in Scheme 1 with Gly $=\beta$-D-glucopyranosyl and $\mathrm{R}=2$-naphthyl has an inhibitor constant $K_{\mathrm{i}}$ of $0.41 \mu \mathrm{M}$ against rabbit muscle glycogen phosphorylase b) and thus have potential in developing new pharmacological treatments of diseases wherein the regulation of glycogen metabolism plays significant roles, e.g. in type 2 diabetes, cerebral and cardiac ischemias, and tumor growth. ${ }^{7,8}$

The synthesis of compounds $\mathbf{J}$ by applying $C$-glycosyl acylamidrazone intermediates was not straightforward due to unexpected bifurcation of these reactions leading to either 1,3,4oxadiazoles or the desired 1,2,4-triazoles. ${ }^{9}$ The first efficient preparation of $O$-perbenzoylated 3- $\beta$-D-glucopyranosyl-5substituted-1,2,4-triazoles $\mathbf{J}$ (Scheme 1) was effected by the acylation of tosylamidrazones $\mathbf{D}$ obtained from the readily available glucopyranosyl cyanide A via intermediates $\mathbf{B}$ and $\mathbf{C}$ in altogether 4 synthetic steps. ${ }^{7,9}$ A shorter, 3 steps route to $\mathbf{J}$ was elaborated by the $N$-imidoylation of tetrazole $\mathbf{H}$ and subsequent ring closure of the intermediary $C$-glycosyl- $N$-imidoyl nitrilimine followed by removal of the $N$-benzyl protecting group of $\mathbf{I}^{\mathbf{8}}$

Given the importance of this compound class we envisaged that an even shorter sequence could lead from $\mathbf{A}$ to $\mathbf{J}$ via the oxidative ring closure of $\mathrm{N}$-glycosylmethylidene-amidrazones $\mathbf{F}$. The preparation of $\mathbf{F}$ was foreseen through the adaptation of our method to get various $C$-glycosyl-imine derivatives by Raney $\mathrm{Ni}{ }^{\circledR}$ reduction of $\mathbf{A}$ in the presence of $e . g$. hydrazine derivatives. ${ }^{\mathbf{1 0 - 1 2}}$ 


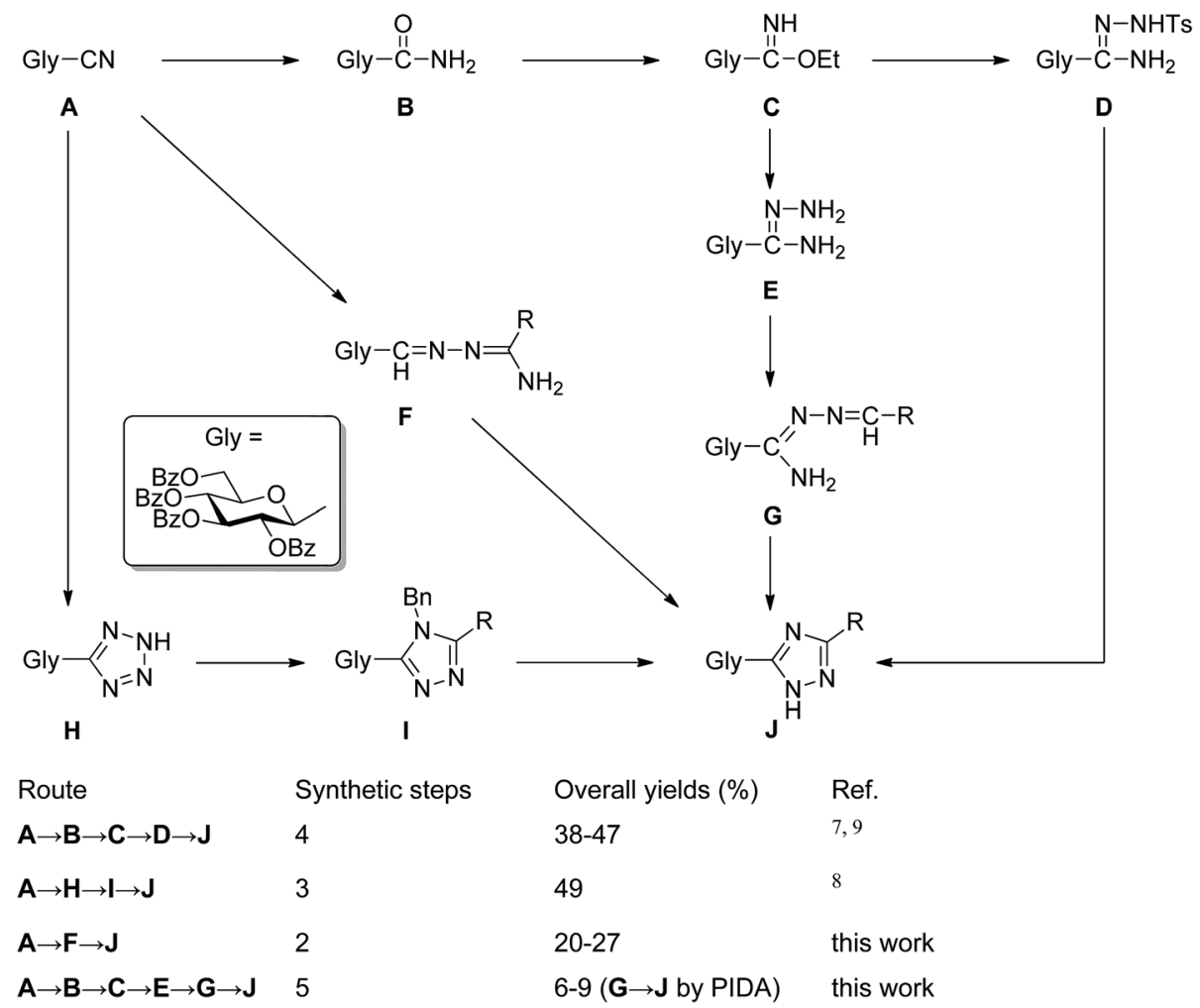

Scheme 1 Synthetic routes towards 3-glycosyl-5-substituted-1,2,4-triazoles.

Construction of five membered aromatic heterocycles with three heteroatoms in the 1,2,4-(or 1,3,4-) positions is frequently based on oxidative ring closing reactions of $N$-acyl-hydrazones and analogous compounds (Scheme 2): thus, $\mathrm{N}$-acyl- and $\mathrm{N}$ thioacyl-hydrazones $\mathbf{K}$ give the corresponding 1,3,4-oxa- and -thiadiazoles $\mathbf{L}$, respectively. The analogous formation of 1,2,4triazoles is also known, however, this method is almost exclusively used for the synthesis of various condensed 1,2,4-triazoloheterocycles $\mathbf{R}$ from cyclic amidrazones $\mathbf{Q}^{\mathbf{1 3 , 1 4}}$ (some literature examples using various oxidants: $\mathrm{Br}_{2},{ }^{15} \mathrm{~Pb}(\mathrm{OAc}){ }_{4},{ }^{16,17} \mathrm{NBS},{ }^{18}$ air
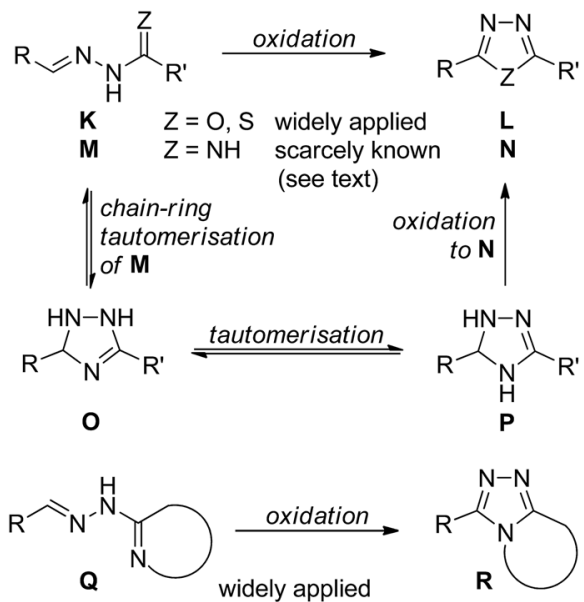

Scheme 2 Oxidative ring closures of $\mathrm{N}$-acyl-hydrazone type compounds.
$\left(\mathrm{O}_{2}\right),{ }^{19}$ and hypervalent iodine reagents $\left.{ }^{20-23}\right)$. Formation of 3,4,5trisubstituted-1,2,4-triazoles from aldehyde tosylhydrazones and Schiff-bases under oxidative conditions (PhIO and NBS) was also reported. ${ }^{24}$

Very few examples are known for the oxidative closure of alkylidene amidrazones $\mathbf{M}$ to give the corresponding 1,2,4-triazoles $\mathbf{N}$ : to the best of our knowledge oxidations by $\mathrm{HgO}^{25,26}$ or $\mathrm{Ag}_{2} \mathrm{O}^{25}$ to give 3,4,5-trisubstituted-1,2,4-triazoles as well as dehydrogenations at elevated temperature by $\operatorname{Pd}(C)^{27,28}$ to 3,5 disubstituted-1,2,4-triazoles were reported only. In some cases the formation of triazoline $\mathbf{O}$ (actually a ring tautomer of $\mathbf{M}$ ) from amidrazones and carbonyl compounds was postulated ${ }^{29}$ whose oxidation (also from other tautomers, e.g. P) gave the triazole $\mathbf{N}^{30}$

Based on these preliminaries we have undertaken the synthesis of $\mathrm{N}$-glycosylmethylidene-amidrazones $\mathbf{F}$ and studying their oxidative reactions. Although it represents a longer route towards 1,2,4-triazoles $\mathbf{J}$, preparation of some $\mathrm{N}$-arylidene- $\mathrm{C}$ glycosyl-amidrazones $\mathbf{G}$ and their oxidation has also been carried out to reveal any possible effect of the different substitution pattern of the amidrazone moiety. In addition, the extension of these studies to aromatic derivatives to investigate a broader functional group tolerance is also reported.

\section{Results and discussion}

Syntheses of sugar derived alkylidene amidrazones were accomplished by adapting literature protocols. Thus, glycosyl cyanides $1,{ }^{31} 2,{ }^{32}$ or $3^{33,34}$ were reacted with aminoguanidine (4) 




Scheme 3 Synthesis of $N^{1}$-glycosylmethylidene-amidrazones.

and aromatic carboxamidrazones 5-7 (preparation described in our earlier paper ${ }^{9}$ ) under reductive conditions ${ }^{10-12}$ to give the corresponding glycosylmethylidene amidrazones 8-13 in medium yields (Scheme 3).

$O$-Perbenzoylated $\quad N^{1}$-arylidene- $C$-glucopyranosyl formamidrazones 18-20 were obtained in reactions of amidrazone $14^{9}$ and the corresponding aldehydes 15-17 (Scheme 4).

Alkylidene amidrazones 8-13 and 18-20 exist in the 'open' tautomeric forms ( $c f$. Scheme 2) as depicted in Schemes 3 and 4 , respectively, that is indicated by two $\mathrm{C}=\mathrm{N}$ resonances ${ }^{35}$ in their ${ }^{13} \mathrm{C}$ NMR spectra in the range of $150-160 \mathrm{ppm}$. No special efforts were made to determine the tautomeric equilibria with regard to the position of the $\mathrm{NH}$ protons, however, this seems different in these compounds based on the chemical shift of exchangable proton signals (see ESI $\dagger$ ). Therefore, both tautomers $a$ and $b$ may be present and are shown in the respective schemes.

Oxidation of the above amidrazones was tried under a variety of conditions (e.g. $\mathrm{Pb}(\mathrm{OAc})_{4}$ in $\mathrm{CH}_{3} \mathrm{CN}, \mathrm{K}_{3}\left[\mathrm{Fe}(\mathrm{CN})_{6}\right]$ in EtOH or $\mathrm{CH}_{3} \mathrm{CN}, \mathrm{MnO}_{2}$ in $\mathrm{CH}_{2} \mathrm{Cl}_{2}, \mathrm{KMnO}_{4}$ in $\mathrm{CH}_{3} \mathrm{COOH}$ at r. t. to reflux temperatures for $\mathbf{9}, \mathrm{HgO}$ in $m$-xylene, DDQ in THF at $\mathrm{r}$. t. to reflux temperatures for 18), however, these reactions gave complex product mixtures not worth for tracking down their components. On the other hand, reactions with PIDA or NBS gave cleaner transformations whose product mixtures could be either separated by column chromatography or analysed by LCMS methods.

Reactions of alkylidene amidrazones (Table 1, compound type IV) with PIDA resulted in product mixtures each of which contained the expected 1,2,4-triazoles of type $\mathbf{V}$ either detected (entries 1-4) or isolated (entries 2 and 3 ) albeit in very low yields. In addition to triazoles $\mathbf{V}$ other compounds, such as nitriles VI, acetates VII, and alkylated triazoles VIII were also identified in the mixtures wherein VI and VII proved to be the main



Scheme 4 Synthesis of $N^{1}$-arylidene-C-glycosyl formamidrazones.

products which could be isolated in good yields in most cases (entries 2-4).

Based on the analysis of the product mixtures and the generally accepted reactivity pattern of diacyloxy-iodobenzene reagents ${ }^{13}$ a mechanistic proposal has been set up to explain the outcome of these reactions (Scheme 5). For the sake of simplicity only tautomers $b$ are shown for alkylidene amidrazones IV. Thus, nucleophilic attack by the $\mathrm{N}^{1}$ nitrogen of IV onto PIDA (route A) may give ion pair I which by loss of AcOH and intramolecular addition of $\mathrm{N}^{3}$ to the carbeniumion next to $\mathrm{R}^{1}$ results in II. Reductive elimination of $\mathrm{PhI}$ and concomitant deprotonation of II end in the formation of 3,5-disubstituted1,2,4-triazoles V. Attack of PIDA by $\mathbf{N}^{2}$ of amidrazone $\mathbf{~ V}$ (route $B$ ) may give intermediate III which, upon loss of $\mathrm{PhI}$ and $\mathrm{AcOH}$ and subsequent tautomerisation, results in V. PIDA may also be attacked by the $\mathbf{N}^{3}$ nitrogen of $\mathbf{I V}$ (route $C$ ) to give IX from which the reductive elimination-deprotonation sequence results in a fragmentation to nitrile $\mathbf{V I}$ and diazo compound $\mathbf{X}$. The latter may alkylate the $\mathrm{AcOH}$ present in the mixture to give acetate VII. Alkylation of any tautomer of the triazole $\mathbf{V}$ by $\mathbf{X}$ may lead to isomeric $N$-alkyl triazoles VIII. Route $C$ may be less probable if the $\mathrm{R}^{2}-\mathrm{C}-\mathrm{N}^{3}$ moiety of amidrazone $\mathbf{I V}$ is part of a ring, therefore, high yielding formation of triazole $\mathbf{V}$ can be observed in such cases as reported many times in the literature to give fusedtriazole derivatives ( $c f$. Introduction).

Next, oxidations by NBS were tried with $N^{1}$ glycosylmethylidene-amidrazones 8-13 (Table 2). Each amidrazone gave the corresponding bromo derivative 24-29 with NBS in $\mathrm{CH}_{2} \mathrm{Cl}_{2}$ at r. t. in good yield in most cases. These bromides proved surprisingly stable and could be purified by column chromatography. The position of the bromine was identified on the basis of changes in the ${ }^{1} \mathrm{H}$ NMR spectra: while for the starting compounds 8-11 a double doublet was to be observed in the range of $4.48-4.66 \mathrm{ppm}$ for $\mathrm{H}-1$, this proton showed a doublet around 4.76-4.78 ppm for 24-27. The H-1 signals appeared at 4.22 (dd) and 4.36 (d) for 13 and 29, respectively. The resonances for $\mathrm{H}-1$ in the brominated derivatives 24-29 characteristically shifted downfield by $0.1-0.3 \mathrm{ppm}$ in comparison to those in the parent compounds 8-13. In the 
Table 1 Reactions of sugar derived $N^{1}$-alkylidene-amidrazones with PIDA ${ }^{a}$

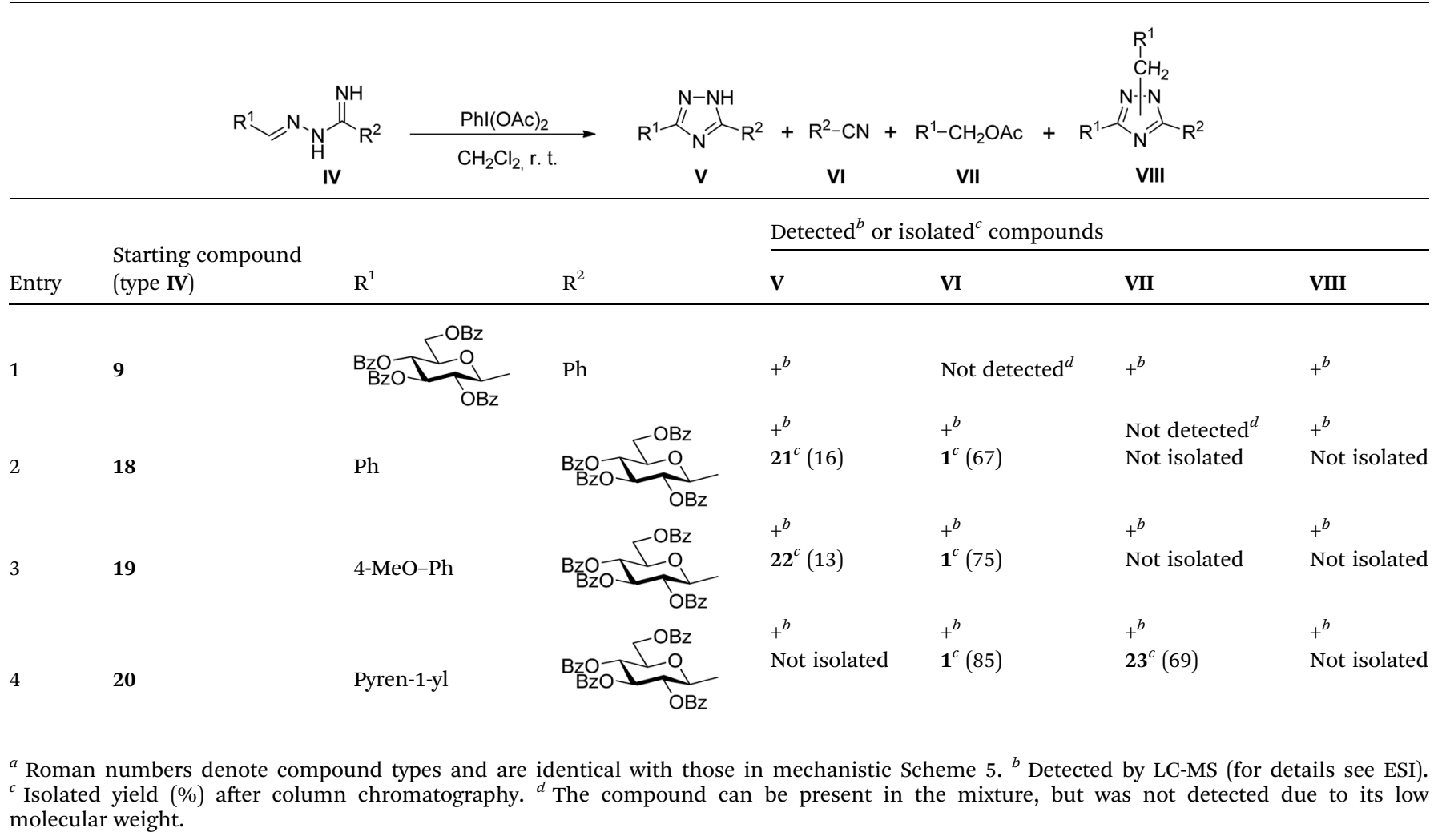

${ }^{13} \mathrm{C}$ spectra the bromination caused a downfield shift of a sugar carbon to $\sim 82 \mathrm{ppm}$. On the other hand, the resonance of the glycosylmethylidene carbon $(\mathrm{CH}=\mathrm{N}$ around $151 \mathrm{ppm}$ in 9-13) shifted upfield by $\sim 20 \mathrm{ppm}$ in the brominated compounds $(\mathrm{CBr}=\mathrm{N}$ around $130-132 \mathrm{ppm}$ in 25-29) due to the heavy atom effect. ${ }^{36}$

Ring closure of the bromides was attempted in two ways: by heating in $\mathrm{AcOH}$ in the presence of $\mathrm{NH}_{4} \mathrm{OAc}$ (conditions $\mathrm{A}$ in Table 2) or by boiling in dry pyridine (conditions B). Transformation of $\mathbf{2 4}$ resulted in complex reaction mixtures under both conditions. With other bromides 25-29 formation of 1,2,4triazoles 21, 30-33, respectively, could be effected in acceptable to good yields whereby none of the applied methods proved superior to the other one.

Under similar conditions the reaction of $N^{1}$-benzylidene- $C$ glucopyranosyl form amidrazone 18 with NBS gave a complex mixture from which no discrete products could be isolated by column chromatography. An LC-MS analysis of this reaction mixture and that of $\mathbf{9}$ is presented in Table 3 showing that the same types of compounds were formed in both reactions. Thus, the presence of the primary hydrazonoyl bromide type products XIII could be justified (see ESI $\dagger$ ), and also the expected triazoles $\mathbf{V}$ were to be observed. Besides these derivatives additional products of type XI derived from two molecules of IV as well as nitriles VI could also be detected (see mechanistic discussion below). The formation of triazoles $\mathbf{V}$ under the bromination conditions prompted experiments to increase the ratio of this product in these circumstances. Therefore, reactions of 9 and 19 with NBS were carried out in the presence or absence of $\mathrm{NH}_{4} \mathrm{OAc}$ in $\mathrm{CH}_{2} \mathrm{Cl}_{2}$, $\mathrm{AcOH}$, or 1,4-dioxane at r. t. or with boiling. However, the isolated yield of the corresponding triazoles $\mathbf{2 1}$ and 22, respectively, did not exceed $25-35 \%$, therefore, the two steps procedure remained more advantageous.

In order to study the broader applicability and functional group tolerance of the above NBS-mediated ring closing reactions, they were extended to several aromatic derivatives. To start these studies, a variety of $N^{1}$-arylidenearenecarboxamidrazones $\mathbf{3 5}$ were synthesized by the reaction of ethyl benzimidate (34) with aldehyde-hydrazones in dry EtOH at reflux temperature (conditions $A$ in Scheme 6) in moderate to good yields (Table 4). Better yields were achieved when alkylidene-amidrazones $\mathbf{3 5}$ and $\mathbf{3 6}$ were obtained in a condensation reaction of benzamidrazone (5) or pyridine-2carboxamidrazone (6), respectively, with aromatic aldehydes in dry EtOH at reflux temperature (conditions $B$ in Scheme 6, Table 4).

In the reactions of $\mathbf{3 5}$ and $\mathbf{3 6}$ with NBS no attempts were made to isolate the putative intermediate carbohydrazonoyl bromides $\mathbf{3 7}$ and $\mathbf{3 8}$ which, as crude products, were transformed to the desired triazoles 39 and 40, respectively (conditions $C$ in Scheme 6). In these reactions 5-aryl-4-arylidenamino-3-phenyl1,2,4-triazoles ${ }^{37} \mathbf{4 1}$ were also isolated $(\mathbf{4 1 a}, \mathbf{4 1 d})$ or detected (41b, 41c, 41e) as by-products. By changing the order of addition of the reagents (conditions $D$ in Scheme 6) formation of triazoles 


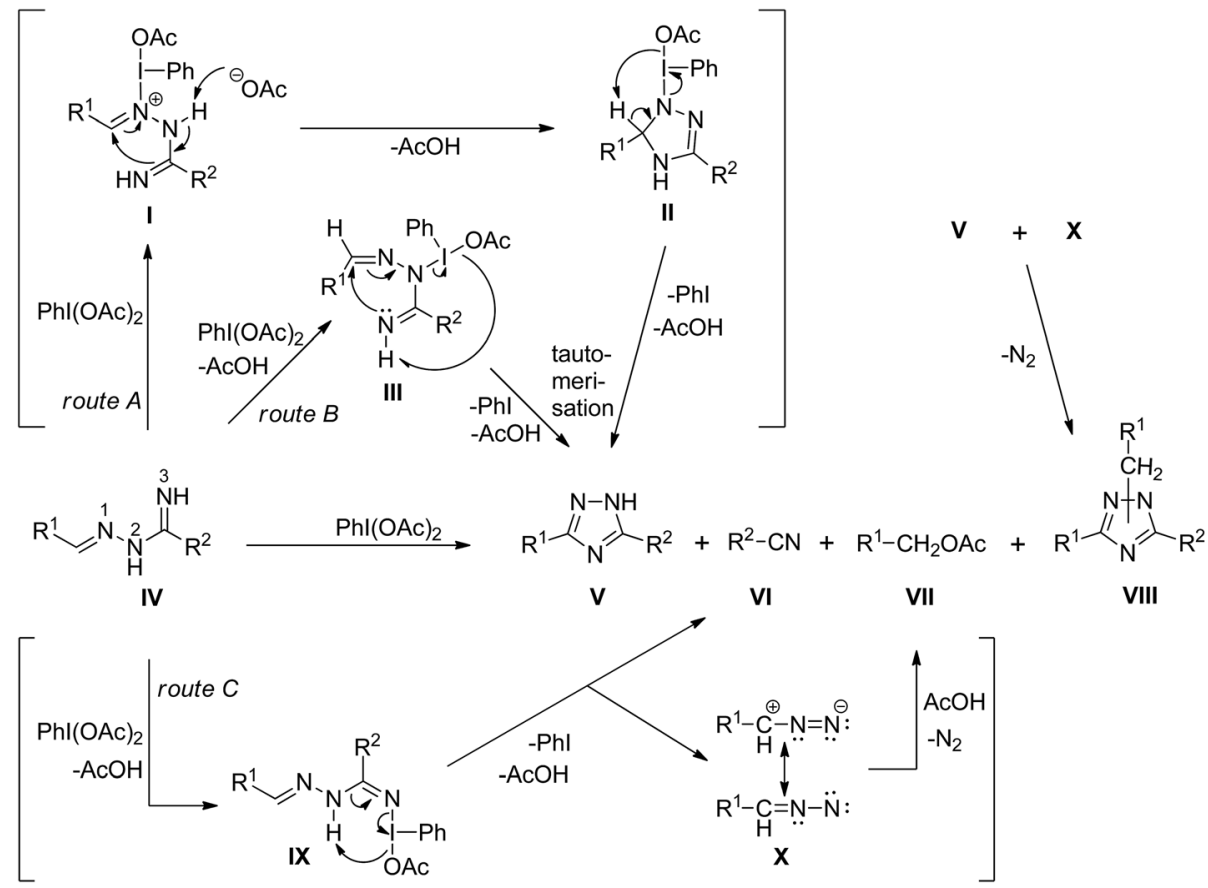

Scheme 5 Proposed mechanism for the reaction of $N^{1}$-alkylidene-amidrazones with PIDA.

41 could be avoided, and the desired products $39 \mathbf{a}-\mathbf{j}$ were obtained in better yields (Table 4). The pyridine derivatives $\mathbf{4 0}$ were prepared only in this way. Amidrazones $35 \mathbf{k}$ and $36 \mathbf{k}$ with a free $\mathrm{OH}$ group resulted in complex reaction mixtures in both conditions $C$ and $D$, while 36e containing a methylsulfanyl group (MeS) was converted to the corresponding sulfoxide 40e.

To understand the formation of the isolated and observed products in the NBS-mediated reactions a mechanistic rationale is proposed in Scheme 7. $N^{1}$-Alkylidene amidrazones IV are brominated to give the hydrazonoyl bromide type compounds XIII from which the $\mathrm{R}^{1}=$ Gly derivatives (24-29) proved sufficiently stable and could also be isolated. Intramolecular ring closure of XIII may directly give triazoles $\mathbf{V}$ and this may be facilitated by the removal of $\mathrm{HBr}$ in the presence of a basic solvent (reactions in pyridine) or an added base (reactions in the presence of $\mathrm{NH}_{4} \mathrm{OAc}$ ). In reactions with $\mathrm{NH}_{4} \mathrm{OAc}$ the

Table 2 Transformation of $N^{1}$-glycosylmethylidene-amidrazones to $C$-glycosyl-1,2,4-triazoles by bromination and subsequent ring closure

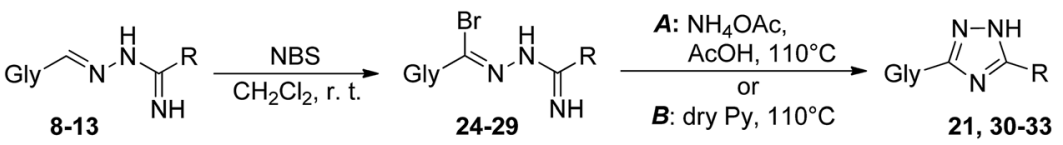

Isolated yield (\%)

Triazole formation

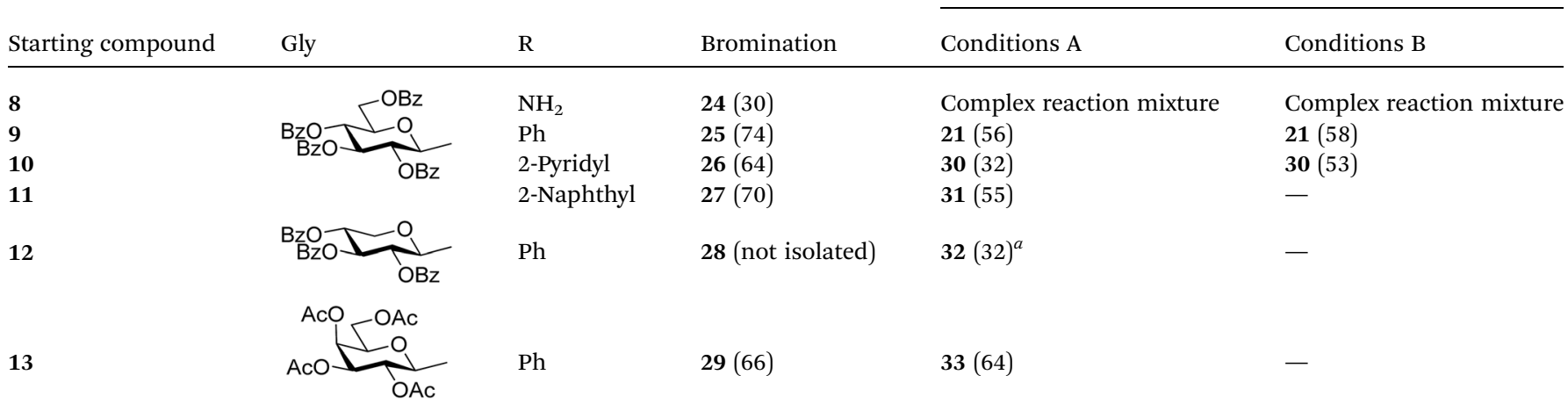

${ }^{a}$ Obtained from crude 28, yield for the two steps. 
Table 3 LC-MS analysis of reaction mixtures of sugar derived $N^{1}$-alkylidene-amidrazones with $\mathrm{NBS}^{a}$

Starting compound
Entry
(type IV)

\footnotetext{
${ }^{a}$ Roman numbers denote compound types and are identical with those in mechanistic Scheme $7 .{ }^{b}$ Detected by LC-MS (for details see ESI). ${ }^{c}$ Isolated yield (\%) after column chromatography. ${ }^{d}$ The compound can be present in the mixture, but was not detected due to its low molecular weight. ${ }^{e}$ Detectable form: $\mathrm{Br} \rightarrow \mathrm{OH}$.
}

ammonium salt may act as a source of $\mathrm{NH}_{3}$ and this may lead to the formation of XII ( $N^{1}$-carboximido-amidrazones) which can ring close to triazoles $\mathbf{V}$ that was demonstrated with isolated compounds XII earlier. ${ }^{9}$ Hydrazonoyl bromides XIII may be prone to loss of bromide ion to form carbocation XIV as it was made likely in kinetic studies of several hydrazonoyl halides. ${ }^{\mathbf{3 8 - 4 0}}$ Cation XIV may form the triazole V directly or via XII depending on the reaction conditions. The presence of this cation in the reaction mixtures may also account for the formation of the observed/isolated by-products. 4-Alkylideneamino-3,5disubstituted-1,2,4-triazoles XI are analogues of known symmetric 4-arylideneamino-3,5-diaryl-1,2,4-triazoles obtained by chlorination of $N$-alkylidene hydrazides. ${ }^{37}$ Formation of XI can be envisaged by an attack of unreacted alkylideneamidrazone IV on cation XIV to give intermediate $\mathbf{X V}$ which upon ring closure accompanied by loss of $\mathrm{NH}_{3}$ may yield tetrazepine XVI. Subsequent extrusion of nitrile VI with concomitant formation of the 1,2,4-triazole ring give compounds XI which were isolated in the aromatic series $(\mathbf{4 1 a}, 41 d)$ and identified by mass spectrometry in the reactions of the sugar derived amidrazones $\mathbf{9}$ and $\mathbf{1 8}$.

\section{Conclusion}

Oxidative ring closing conditions were studied for the preparation of unsymmetrical 3,5-disubstituted-1,2,4-triazoles from acyclic $N^{1}$-alkylidene-carboxamidrazones. Although among others also PIDA proved unsuitable for this transformation, based on detailed analyses of the reaction mixtures, a mechanistic proposal was set up to rationalize the success of this reagent in obtaining fused 1,2,4-triazoles. NBS and $O$-peracylated $N^{1}$-(glycopyranosylmethylidene)-arenecarboxamidrazones gave stable and isolable hydrazonoyl bromide type compounds which were ring closed to the corresponding $C$ glycosyl-1,2,4-triazoles under basic conditions. Extension of the method to aromatic substrates revealed that NBS in $\mathrm{AcOH}$ in the presence of $\mathrm{NH}_{4} \mathrm{OAc}$ was a generally applicable reagent combination to get the target compounds. A mechanistic rationale was proposed to account for the formation of byproducts in these transformations. With this study we have demonstrated that $N^{1}$-alkylidene-amidrazones can be transformed into 3,5-disubstituted-1,2,4-triazoles with different groups attached to the carbon atoms of the heterocycle. The

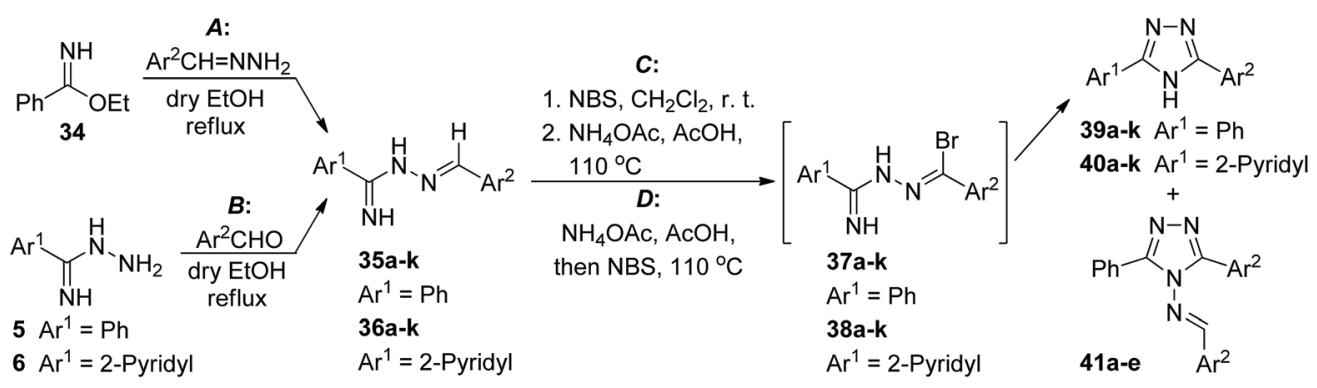

Scheme 6 Syntheses of $N^{1}$-arylidene-arenecarboxamidrazones and their transformation into 3,5-diaryl-1,2,4-triazoles. 
RSC Advances

Paper

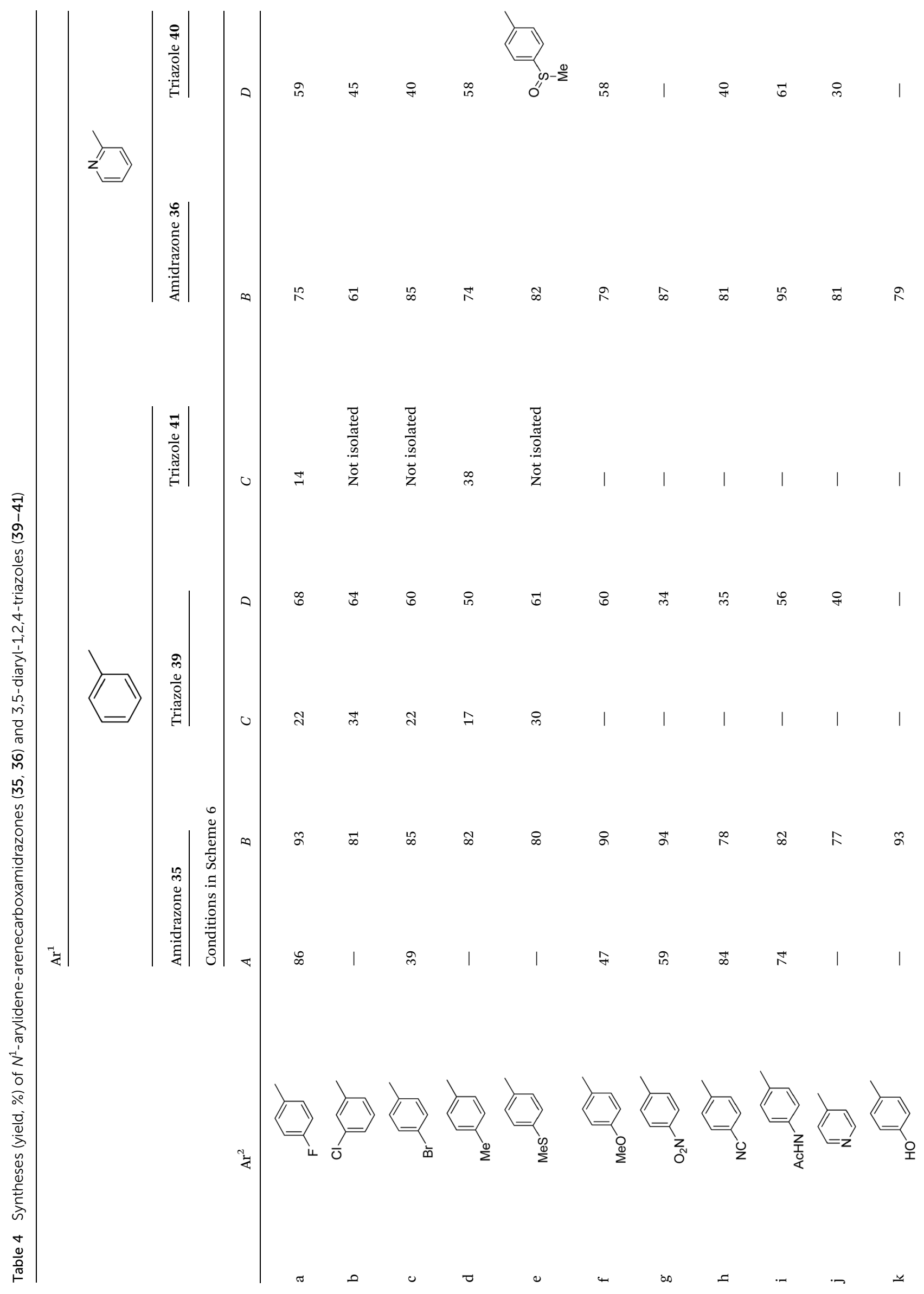

43626 | RSC Adv., 2015, 5, 43620-43629

This journal is (C) The Royal Society of Chemistry 2015 


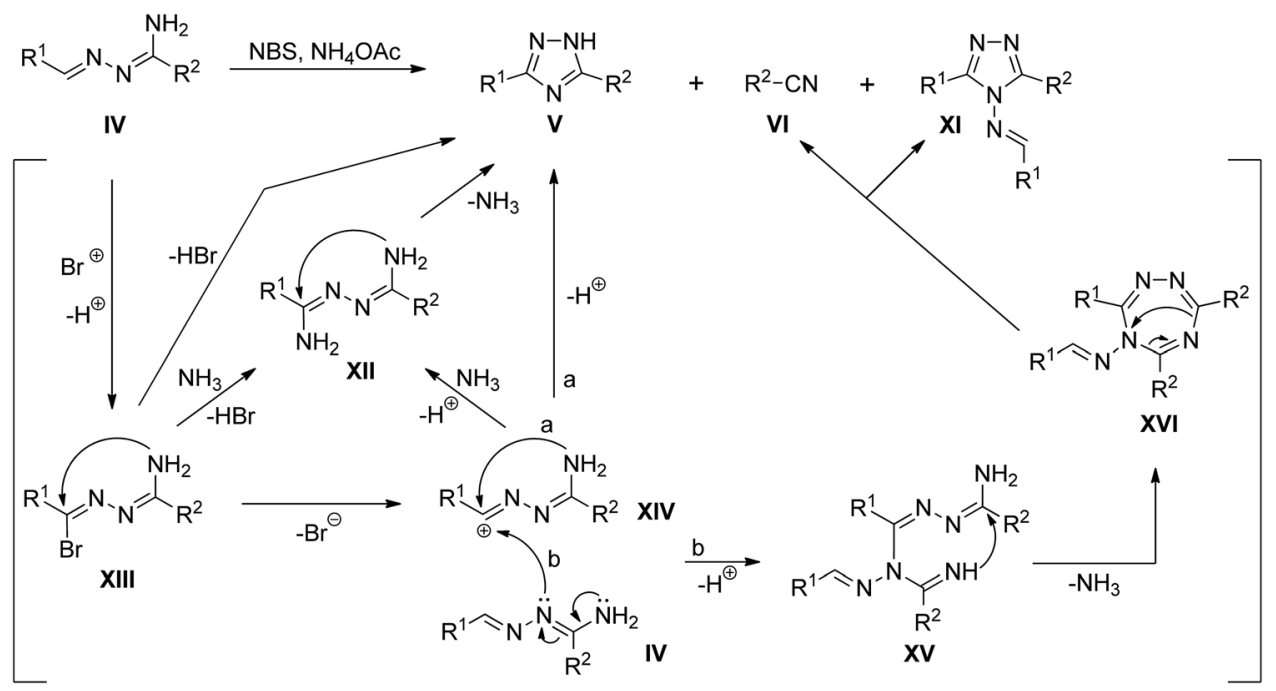

Scheme 7 Mechanistic proposal for the reaction of $N^{1}$-alkylidene-amidrazones with NBS.

method constitutes the shortest synthetic route to $3-\left(\beta-\mathrm{D}^{-}\right.$ glycopyranosyl)-5-substituted-1,2,4-triazoles, among which the glucose derivatives belong to the most efficient inhibitors of glycogen phosphorylase, and are thereby potential antidiabetic agents.

\section{Experimental}

\section{General methods}

Melting points were measured in open capillary tubes or on a Kofler hot-stage and are uncorrected. Optical rotations were determined with a Perkin-Elmer 241 polarimeter at room temperature. NMR spectra were recorded with Bruker 360 (360/90 $\mathrm{MHz}$ for $\left.{ }^{1} \mathrm{H} /{ }^{13} \mathrm{C}\right)$ or Bruker $400\left(400 / 100 \mathrm{MHz}\right.$ for $\left.{ }^{1} \mathrm{H} /{ }^{13} \mathrm{C}\right) \mathrm{spec}-$ trometers. Chemical shifts are referenced to TMS as the internal reference $\left({ }^{1} \mathrm{H}\right)$, or to the residual solvent signals $\left({ }^{13} \mathrm{C}\right)$. Microanalyses were performed on an Elementar vario Micro cube. LCMS was performed on a Hypersil Gold $(50 \times 2.1 \mathrm{~mm}, 1.9 \mu \mathrm{m}$, with precolumn filter, Thermo Electron Corp., San Jose, CA, USA) column, using an Accela HPLC system (Thermo Electron Corp., San Jose, CA, USA) coupled with a Thermo LTQ XL mass spectrometer (Thermo Electron Corp., San Jose, CA, USA) operated in a full scan positive ion ESI mode or with a Bruker micrOTOF-Q instrument. TLC was performed on DC-Alurolle Kieselgel 60 $\mathrm{F}_{254}$ (Merck). TLC plates were visualized under UV light, and by gentle heating. For column chromatography Kieselgel 60 (Merck, particle size $(0.063-0.200 \mathrm{~mm})$ was applied. Organic solutions were dried over anhydrous $\mathrm{MgSO}_{4}$, and concentrated under diminished pressure at $40-50{ }^{\circ} \mathrm{C}$ (water bath).

General procedure I for the synthesis of $O$-peracylated $N-[C-(\beta-$ D-glycopyranosyl)methylideneamino]guanidine (8) and $N^{1}-[C$ $(\beta$-D-glycopyranosyl)methylidene]arene-carboxamidrazones

Aminoguanidine $\times \mathrm{H}_{2} \mathrm{CO}_{3}(4,0.50 \mathrm{mmol})$ or an arenecarboxamidrazone $(5-7,0.50 \mathrm{mmol})$ was dissolved in a mixture of pyridine $(1.5 \mathrm{~mL})$ and $\mathrm{H}_{2} \mathrm{O}(0.9 \mathrm{~mL})$, and stirred for 20 min at $\mathrm{r}$. t. Then $\mathrm{AcOH}(0.9 \mathrm{~mL})$, Raney-Ni ${ }^{\circledR}(0.38 \mathrm{~g}$, from an aqueous suspension, Merck), $\mathrm{NaH}_{2} \mathrm{PO}_{2}(0.20 \mathrm{~g}, 2.27 \mathrm{mmol})$, and the corresponding $O$-peracylated $\beta$-D-glycopyranosyl cyanide (1-3, $0.25 \mathrm{mmol}$ ) were added to the mixture. The reaction mixture was vigorously stirred and heated at $40{ }^{\circ} \mathrm{C}$. When the reaction was complete (TLC, EtOAc/hexane $=1: 2$ ) the insoluble materials were filtered off with suction, and washed with $\mathrm{CH}_{2} \mathrm{Cl}_{2}(10$ $\mathrm{mL})$. The organic layer of the filtrate was separated, washed with $\mathrm{H}_{2} \mathrm{O}(2 \times 6 \mathrm{~mL})$, dried $\left(\mathrm{MgSO}_{4}\right)$, and evaporated in vacuo, traces of pyridine were removed by repeated co-evaporations with toluene. The residue was purified by column chromatography.

General procedure II for the synthesis of $N^{1}$-arylidene- $C$ $(2,3,4,6$-tetra- $O$-benzoyl- $\beta$-D-glucopyranosyl)formamidrazones (18-20)

$C$-(2,3,4,6-Tetra-O-benzoyl- $\beta$-D-glucopyranosyl)formamidrazone ${ }^{9}$ $(14,1.0 \mathrm{~g}, 1.57 \mathrm{mmol})$ and the corresponding aromatic aldehyde (15-17, 1.1 equiv.) was heated in dry EtOH $(20 \mathrm{~mL})$ at reflux temperature, and the reaction was monitored by TLC (EtOAc/ hexane $=1: 1$ ). After total consumption of the starting formamidrazone the product was separated either by filtration or by column chromatography.

General procedure III for the transformation of $\boldsymbol{N}^{\mathbf{1}}$-arylidene$C$-(2,3,4,6-tetra- $O$-benzoyl- $\beta$-D-glucopyranosyl) formamidrazones (18-20) by PIDA

To a solution of the corresponding arylidene amidrazone (1820, $0.10 \mathrm{~g}$ ) in dry $\mathrm{CH}_{2} \mathrm{Cl}_{2}$ (3 mL) PIDA (2 equiv.) was added and the reaction mixture was stirred at $r$. $t$. After disappearance of the starting material monitored by TLC $($ EtOAc/hexane $=1: 1)$ the mixture was diluted with $\mathrm{CH}_{2} \mathrm{Cl}_{2}(15 \mathrm{~mL})$, extracted with water $(10 \mathrm{~mL})$, satd aq $\mathrm{NaHCO}_{3}$ solution $(10 \mathrm{~mL})$, and then with water $(10 \mathrm{~mL})$. The organic phase was dried over $\mathrm{MgSO}_{4}$, filtered the solvent was evaporated under reduced pressure. The resulting products were separated by column chromatography. 
General procedure IV for the synthesis of $O$-peracylated $N$ arenecarboximidoyl- $C$-( $\beta$-D-glycopyranosyl)carbohydrazonoyl bromides (24-29)

An alkylidene amidrazone (8-13, $0.28 \mathrm{mmol}$ ) was dissolved in $\mathrm{CH}_{2} \mathrm{Cl}_{2}(4 \mathrm{~mL})$, then $N$-bromosuccinimide $(0.05 \mathrm{~g}, 0.28 \mathrm{mmol})$ was added. The mixture was stirred at $\mathrm{r}$. $\mathrm{t}$. When the reaction was complete (TLC, EtOAc/hexane $=1: 2$ ) the solvent was evaporated, and the residue was purified by column chromatography.

General procedure $\mathrm{V}$ for the synthesis of $O$-peracylated 3-( $\beta$-Dglycopyranosyl)-5-substituted-1,2,4-triazoles (21, 30-33)

A carbohydrazonoyl bromide (24-29, $0.14 \mathrm{mmol}$ ) was dissolved in glacial $\mathrm{AcOH}(3 \mathrm{~mL})$, then $\mathrm{NH}_{4} \mathrm{OAc}(0.012 \mathrm{~g}, 0.15 \mathrm{mmol})$ was added. The mixture was stirred and heated at $110^{\circ} \mathrm{C}$. When the reaction was complete $(\mathrm{TLC}$, EtOAc/toluene $=2: 7)$ the mixture was diluted with $\mathrm{H}_{2} \mathrm{O}(6 \mathrm{~mL})$, and washed with $\mathrm{CH}_{2} \mathrm{Cl}_{2}(3 \times 7$ $\mathrm{mL})$. The organic layer was separated and washed with cold, saturated $\mathrm{NaHCO}_{3}$ solution $(8 \mathrm{~mL})$, and $\mathrm{H}_{2} \mathrm{O}(8 \mathrm{~mL})$, dried $\left(\mathrm{MgSO}_{4}\right)$, and evaporated under reduced pressure. The residue was purified by column chromatography.

General procedure VI for the synthesis of $O$-peracylated 3-( $\beta$-Dglycopyranosyl)-5-substituted-1,2,4-triazoles (21, 30)

A carbohydrazonoyl bromide (24-26, $0.10 \mathrm{mmol})$ was dissolved in anhydrous pyridine $(6 \mathrm{~mL})$. The mixture was stirred and heated at $110{ }^{\circ} \mathrm{C}$. The reaction was monitored by TLC (EtOAc/ toluene $=1: 3$ ). When the reaction was complete the solvent was evaporated under reduced pressure. The residue was purified by column chromatography.

General procedure VII for the synthesis of $\boldsymbol{N}^{\mathbf{1}}$-arylidenebenzamidrazones (35)

Ethylbenzimidate $(\mathbf{3 4}, 1.01 \mathrm{mmol})$ was dissolved in dry EtOH (10 $\mathrm{mL}$ ), and the corresponding aryl hydrazone $(1.01 \mathrm{mmol})$ was added. The reaction mixture was stirred and heated at reflux temperature overnight. The reaction was monitored by TLC (EtOAc/hexane $=1: 3$ ). When the reaction was complete the solvent was evaporated under reduced pressure, and the residue was crystallized from ethanol-hexane mixture.

General procedure VIII for the synthesis of $\boldsymbol{N}^{\mathbf{1}}$-arylidenearenecarboxamidrazones $(35,36)$

An arenecarboxamidrazone ( $5{ }^{9}$ or $6,{ }^{41} 1.1 \mathrm{mmol}$ ) was dissolved in dry EtOH $(8 \mathrm{~mL})$, and the corresponding aromatic aldehyde $(1.21 \mathrm{mmol})$ was added. The reaction mixture was stirred and heated at reflux temperature. The reaction was monitored by TLC (EtOAc/hexane $=1: 2$ ). When the reaction was complete the solvent was evaporated under reduced pressure, and the residue was crystallized from ethanol-hexane mixture.
General procedure IX for the synthesis of unsymmetrical 3,5disubstituted-1,2,4-triazoles $(39,40)$

An arylidene amidazone (35 or 36, $0.331 \mathrm{mmol}$ ) was dissolved in $\mathrm{CH}_{2} \mathrm{Cl}_{2}(10 \mathrm{~mL})$, and NBS $(0.059 \mathrm{~g}, 0.331 \mathrm{mmol})$ was added. The reaction mixture was stirred at room temperature. When the reaction was complete (TLC, EtOAc/hexane $=1: 3$ ) the solvent was evaporated under reduced pressure. The crude product was dissolved in glacial acetic acid $(8 \mathrm{~mL})$, then ammonium acetate $(0.028 \mathrm{~g}, 0.364 \mathrm{mmol})$ was added. The reaction mixture was stirred and heated at $110{ }^{\circ} \mathrm{C}$ overnight. When the reaction was complete (TLC, EtOAc/toluene $=1: 3$ ) the mixture was diluted with $\mathrm{H}_{2} \mathrm{O}(30 \mathrm{~mL})$, and washed with EtOAc $(4 \times 15 \mathrm{~mL})$. The organic layer was separated, and washed with water $(15 \mathrm{~mL})$, dried $\left(\mathrm{MgSO}_{4}\right)$, and evaporated under reduced pressure. The residue was purified by column chromatography (EtOAc/hexane $=1: 2$ ).

General procedure $X$ for the synthesis of unsymmetrical 3,5disubstituted-1,2,4-triazoles $(39,40)$

An arylidene amidazone (35 or $36,0.83 \mathrm{mmol}$ ) and ammonium acetate $(0.13 \mathrm{~g}, 0.1 .66 \mathrm{mmol})$ was dissolved in glacial AcOH (16 $\mathrm{mL}$ ), then NBS (0.148 g, $0.83 \mathrm{mmol})$ was added. The mixture was stirred and heated at $110{ }^{\circ} \mathrm{C}$ overnight. When the reaction was complete (TLC, EtOAc/toluene $=1: 3$ ) the mixture was diluted with $\mathrm{H}_{2} \mathrm{O}(30 \mathrm{~mL})$, and washed with EtOAc $(4 \times 15 \mathrm{~mL})$. The organic layer was separated, and washed with water $(15 \mathrm{~mL})$, dried $\left(\mathrm{MgSO}_{4}\right)$, and evaporated under reduced pressure. The residue was purified by column chromatography (EtOAc/hexane $=1: 2)$.

\section{Acknowledgements}

This work was supported by the Hungarian Scientific Research Fund (OTKA 77712 and PD105808), the BAROSS REG_EA_09-12009-0028 (LCMS_TAN) project as well as by TÁMOP-4.2.4.A/211/1-2012-0001 'National Excellence Program' to MT supported by the European Union and the State of Hungary, cofinanced by the European Social Fund.

\section{References}

1 R. Kharb, P. C. Sharma and M. S. Yar, J. Enzyme Inhib. Med. Chem., 2011, 26, 1-21.

2 C. H. Zhou and Y. Wang, Curr. Med. Chem., 2012, 19, 239280.

3 S. Maddila, R. Pagadala and S. B. Jonnalagadda, Lett. Org. Chem., 2013, 10, 693-714.

4 H. X. Ding, C. A. Leverett, R. E. Kyne Jr, K. K. C. Liu, S. J. Fink, A. C. Flick and C. J. O'Donnell, Bioorg. Med. Chem., 2015, 23, 1895-1922.

5 J. B. Polya, in Comprehensive Heterocyclic Chemistry, ed. K. T. Potts, Pergamon, Exeter, 1984, vol. 5, pp. 733-790.

6 A. Moulin, M. Bibian, A.-L. Blayo, S. El Habnouni, J. Martinez and J.-A. Fehrentz, Chem. Rev., 2010, 110, 1809-1827.

7 É. Bokor, T. Docsa, P. Gergely and L. Somsák, ACS Med. Chem. Lett., 2013, 4, 612-615. 
8 S. Kun, É. Bokor, G. Varga, B. Szőcs, A. Páhi, K. Czifrák, M. Tóth, L. Juhász, T. Docsa, P. Gergely and L. Somsák, Eur. J. Med. Chem., 2014, 76, 567-579.

9 É. Bokor, A. Fekete, G. Varga, B. Szőcs, K. Czifrák, I. Komáromi and L. Somsák, Tetrahedron, 2013, 69, 1039110404.

10 M. Tóth and L. Somsák, Tetrahedron Lett., 2001, 42, 27232725.

11 M. Tóth and L. Somsák, Carbohydr. Res., 2003, 338, 13191325.

12 M. Tóth, L. Somsák and D. Goyard, in Carbohydrate Chemistry: Proven Synthetic Methods, ed. P. Kováč, CRC Press, Boca Raton, 2012, vol. 1, pp. 355-365.

13 G. F. Koser, Adv. Heterocycl. Chem., 2004, 86, 225-292.

14 V. V. Zhdankin and P. J. Stang, Chem. Rev., 2008, 108, 52995358.

15 M. S. Gibson, Tetrahedron, 1963, 19, 1587-1589.

16 A. Pollak and M. Tišler, Tetrahedron, 1966, 22, 2073-2079.

17 A. V. Zavodskaya, V. V. Bakharev, V. E. Parfenov, A. A. Gidaspov, P. A. Slepukhin, M. L. Isenov and O. S. Eltsov, Tetrahedron Lett., 2015, 56, 1103-1106.

18 H. J. Chen, Z. H. Shang and J. B. Chang, Synth. Commun., 2006, 36, 445-450.

19 L. J. Guetzoyan, R. A. Spooner, J. M. Lord, L. M. Roberts and G. J. Clarkson, Eur. J. Med. Chem., 2010, 45, 275-283.

20 R. Kumar, R. R. Nair, S. S. Dhiman, J. Sharma and O. Prakash, Eur. J. Med. Chem., 2009, 44, 2260-2264.

21 P. Kumar, Chem. Heterocycl. Compd., 2012, 47, 1237-1243.

22 O. Prakash, D. K. Aneja, K. Hussain, R. Kumar, S. Arora, C. Sharma and K. R. Aneja, J. Heterocycl. Chem., 2012, 49, 1091-1097.

23 D. K. Aneja, P. Ranjan, L. Arora and O. Prakash, C. R. Chim., 2014, 17, 881-889.
24 D. K. Maiti, N. Chatterjee, P. Pandit and S. K. Hota, Chem. Commun., 2010, 46, 2022-2024.

25 A. Spassov, E. Golovinsky and G. Russev, Chem. Ber., 1963, 96, 2996-2999.

26 M. Takahashi, H. Tan, K. Fukushima and H. Yamazaki, Bull. Chem. Soc. Jpn., 1977, 50, 953-956.

27 M. G. Mamolo, L. Vio, E. Banfi and M. Cinco, Eur. J. Med. Chem., 1986, 21, 467-474.

28 L. Vio, M. G. Mamolo and G. Pellizer, Arch. Pharm., 1988, 321, 713-717.

29 F. H. Case, J. Heterocycl. Chem., 1970, 7, 1001-1005.

30 V. V. Pinson, V. A. Khrustalev, K. N. Zelenin and Z. M. Matveeva, Khim. Geterotsikl. Soedin., 1984, 1415-1421.

31 L. Somsák and V. Nagy, Tetrahedron: Asymmetry, 2000, 11, 1719-1727, corrigendum 2247.

32 L. Dong, L. Li, L. Ma and L. Zhang, Chin. Chem. Lett., 1992, 3, 597-600.

33 R. W. Myers and Y. C. Lee, Carbohydr. Res., 1984, 132, 61-85. 34 R. W. Myers and Y. C. Lee, Carbohydr. Res., 1986, 154, 145163.

35 K. N. Zelenin, V. A. Khrustalev and V. P. Sergutina, Zh. Org. Khim., 1980, 16, 942-950.

36 H. Duddeck, in Topics in Stereochemistry, ed. E. L. Eliel, S. H. Wilen and N. L. Allinger, John Wiley \& Sons, Inc., 2007, vol. 16, pp. 219-324.

37 W. Zielinski and W. Czardybon, Chem. Heterocycl. Compd., 2001, 37, 1107-1110.

38 A. F. Hegarty, J. O'Driscoll, J. K. O'Halloran and F. L. Scott, J. Chem. Soc., Perkin Trans. 2, 1972, 1887-1892.

39 A. F. Hegarty, T. A. F. O'Mahony, P. Quain and F. L. Scott, J. Chem. Soc., Perkin Trans. 2, 1973, 2047-2054.

40 A. F. Hegarty, P. Quain, T. A. F. O'Mahony and F. L. Scott, J. Chem. Soc., Perkin Trans. 2, 1974, 997-1004.

41 F. H. Case, J. Org. Chem., 1965, 30, 931-933. 